\title{
Contraception needs and pregnancy termination in sub-Saharan Africa: a multilevel analysis of demographic and health survey data
}

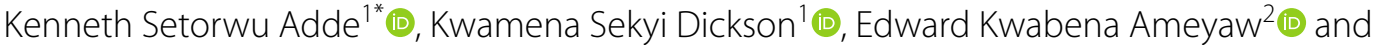 \\ Joshua Amo-Adjei ${ }^{1}$ (D)
}

\begin{abstract}
Background: Women in sub-Saharan Africa (SSA) have a higher risk of unintended pregnancies that are more likely to be terminated, most of which are unsafe with associated complications. Unmet need for contraception is highest in SSA and exceeds the global average. This study investigates the association between unmet/met need for contraception and pregnancy termination SSA.
\end{abstract}

Methods: We used pooled data from Demographic and Health Surveys conducted from January 2010 to December 2018 in 32 countries in SSA. Our study involved 265,505 women with diverse contraception needs and with complete data on all variables of interest. Multilevel logistic regression at $95 \% \mathrm{Cl}$ was used to investigate the association between individual and community level factors and pregnancy termination.

Results: We found an overall pregnancy termination rate of $16.27 \%$ ranging from $9.13 \%$ in Namibia to $38.68 \%$ in Gabon. Intriguingly, women with a met need for contraception were more likely to terminate a pregnancy $[\mathrm{aOR}=1.11 ; 95 \% \mathrm{Cl} 1.07-1.96]$ than women with unmet needs. Women with secondary education were more likely to terminate a pregnancy as compared to those without education $[\mathrm{aOR}=1.23 ; 95 \% \mathrm{Cl} 1.19-1.27]$. With regards to age, we observed that every additional age increases the likelihood of terminating a pregnancy. At the contextual level, the women with female household heads were less likely to terminate a pregnancy [aOR $=0.95 ; 95 \% \mathrm{Cl} 0.92-0.97]$. The least socio-economically disadvantaged women were less likely to terminate a pregnancy compared to the moderately and most socio-economically disadvantaged women.

Conclusions: Our study contributes towards the discussion on unmet/met need for contraception and pregnancy termination across SSA. Women with met need for contraception have higher odds of terminating a pregnancy. The underlying cause of this we argued could be poor adherence to the protocols of contraceptives or the reluctance of women to utilise contraceptives after experiencing a failure. Governments of SSA and non-governmental organisations need to take pragmatic steps to increase met needs for contraception and also utilise mass media to encourage women to adhere to the prescription of contraceptives in order to reduce the incidence of unplanned pregnancies and unsafe abortions.

\footnotetext{
*Correspondence: kenneth.adde@stu.ucc.edu.gh

${ }^{1}$ Department of Population and Health, College of Humanities and Legal

Studies, University of Cape Coast, Cape Coast, Ghana
}

Full list of author information is available at the end of the article

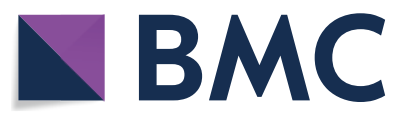

(c) The Author(s) 2021. Open Access This article is licensed under a Creative Commons Attribution 4.0 International License, which permits use, sharing, adaptation, distribution and reproduction in any medium or format, as long as you give appropriate credit to the original author(s) and the source, provide a link to the Creative Commons licence, and indicate if changes were made. The images or other third party material in this article are included in the article's Creative Commons licence, unless indicated otherwise in a credit line to the material. If material is not included in the article's Creative Commons licence and your intended use is not permitted by statutory regulation or exceeds the permitted use, you will need to obtain permission directly from the copyright holder. To view a copy of this licence, visit http://creativecommons.org/licenses/by/4.0/. The Creative Commons Public Domain Dedication waiver (http://creativeco mmons.org/publicdomain/zero/1.0/) applies to the data made available in this article, unless otherwise stated in a credit line to the data. 


\begin{abstract}
Plain language summary
Women in sub-Saharan Africa (SSA) have a higher risk of unintended pregnancies that are more likely to be terminated, most of which are unsafe with associated complications. Unmet need for contraception is highest in SSA and exceeds the global average. This study investigates the association between unmet/met need for contraception and pregnancy termination SSA. We used pooled data from Demographic and Health Surveys conducted from January 2010 to December 2018 in 32 countries in SSA. Our study involved 265,505 women with diverse contraception needs and with complete data on all variables of interest. We found an overall pregnancy termination rate of $16.27 \%$ ranging from $9.13 \%$ in Namibia to $38.68 \%$ in Gabon. Met need of contraception, education, sex of household head, and socioeconomic disadvantage of women had a significant association with pregnancy termination. Our study contributes towards the discussion on unmet/met need for contraception and pregnancy termination across SSA. Governments of SSA and non-governmental organisations need to take pragmatic steps to increase met needs for contraception and also utilise mass media to encourage women to adhere to the prescription of contraceptives in order to reduce the incidence of unplanned pregnancies and unsafe abortions.
\end{abstract}

Keywords: Unmet/met need, Contraception, Unsafe abortion, Pregnancy termination

\section{Background}

Sub-Saharan Africa (SSA) bears the highest burden of global reproductive ill-health with unsafe abortion being one of the most neglected aspects. Global projections indicate that 35 per 1,000 women terminated a pregnancy between 2010 and 2014, denoting 25\% of all pregnancies worldwide and Africa accounted for $8.3 \%$ of all pregnancies terminated [1]. High burden of unintended pregnancies in lower-and middle-income countries (LMICs) occur partly as a result of the unmet need for contraception [2]. Over $75 \%$ of pregnancies terminated in Africa were unsafe [3] and $4.7 \%-13.2 \%$ of maternal deaths globally are attributable to unsafe pregnancy termination [4]. In conjunction with these statistics is the high cost of pregnancy termination borne by the ailing economies of SSA countries. For instance, US\$ 553 million is spent every year to treat complications emerging from unsafe termination of pregnancies [5].

Over 26 years ago, 179 countries including those in SSA pledged to end unsafe pregnancy termination by ensuring that whenever the practice is legalised, it is conducted safely; safeguarding availability and easy access to family planning services; and fostering quality services for managing complications arising from pregnancy termination $[6,7]$. However, due to stigma and restrictive laws across most SSA countries, pregnancy termination in the subregion is mostly clandestine and unsafe thereby posing a major public health threat to women in the reproductive age $[2,8]$. The poor, illiterates, and rural residents are the worst affected in SSA as far as complications of unsafe pregnancy termination are concerned [9].

To circumvent the adverse consequences, evidence highlight the need for effective contraceptive use $[2,10$, 11]. However, unmet need for contraception is highest in SSA (23.4\%) and exceeds the global average of $11.5 \%$. This is only projected to decline to $20.3 \%$ by 2030 [12] with considerable inter-country disparities in contraceptive prevalence in the region [13]. SSA has the lowest demand for contraception globally (49.7\%) which is far below the global average of $77.8 \%$ [13]. Women in SSA, therefore have a higher risk of experiencing pregnancy terminations, most of which may be unsafe with associated complications [9]. Unmet need for contraception is the proportion of women that want to stop/ delay birth but not utilising contraception to prevent pregnancy and include pregnant women whose pregnancies are unplanned/mistimed when they became pregnant, as well as postpartum amenorrhoeic women who are not using family planning and whose last birth was unplanned/mistimed [14].

Hitherto, the few empirical studies that focused on the relationship between unmet need for contraception and pregnancy termination in SSA have been limited to some specific countries such as Ghana [15] and Ethiopia [16] or relied on old datasets [11, 17]. Evidence from these studies converge that the interaction between unmet/met needs for contraception is complex. This study extends the frontiers of evidence on the relationship between contraception needs and occurrence of pregnancy termination in SSA, where a high proportion of pregnancies terminated are unsafe $[2,18]$.

\section{Materials and methods}

Sources of data

This study used the most recent DHS data from 32 countries in SSA that were conducted between January 2010 and December 2018. Specifically, data was extracted from the women's files of the DHS data sets of the countries. The DHS are national surveys carried out every five years in over 90 low- and middle- income countries globally [19]. The DHS concentrates on non-communicable diseases, maternal and child health issues, physical activity, 
sexually transmitted infections, fertility, health insurance, tobacco use, and alcohol consumption. The surveys mainly provide data to monitor the demographic and health profiles of the respective countries [19]. The sample for the present study consisted of women with unmet/ met need for contraceptives (aged 15-49) and had complete cases on all variables of interest $(\mathrm{N}=265,505)$. The DHS program granted us access to the dataset after the evaluation of our concept note. The datasets are freely available to the public at www.measuredhs.com.

\section{Study variables}

\section{Outcome variables}

The outcome variable of this study was ever terminated a pregnancy. This was derived from the question "have you ever had a pregnancy terminated?". It was coded as $0=$ "No" and $1=$ "Yes". Undeniably, due to the measurement approach, this variable may include some spontaneous abortion cases. However, the range of induced abortion found in this study $(9.13 \%-38.68 \%)$ and the average $(16.27 \%)$ are comparable to the prevalence reported from some of the countries included in this study such as Burkina Faso (12\%) [20], Nigeria (23\%) [21], Ghana $(24 \%-25 \%)$ [15, 22] and Ethiopia (33.6\%) [23]. This shows that the majority of the reported prevalence in this study are induced abortions and as such findings and recommendations from the study may be instructive to governments of sub-Saharan Africa.

\section{Explanatory variables}

The main explanatory variable was unmet/met need for contraception and thirteen other explanatory variables were considered as well. All these variables were grouped into individual and contextual level variables based on the hierarchical nature of the dataset. The variables were selected based on their availability in the dataset, practical significance and theoretical relevance for unmet/met need for contraception and pregnancy termination in previous studies $[15,24,25]$.

\section{Individual level}

Unmet/met need for contraception was accompanied by these responses: never had sex, unmet need for spacing, unmet need for limiting, no unmet need, not married and no sex in the last 30 days, and infecund and menopausal. Women who had never had sex, and infecund/menopausal women were excluded from the analysis because they were not exposed to the contraceptive need measurement $[15,25]$. We then generated a binary measure of contraception needs by coding the rest of the responses into 'unmet need' (unmet need for spacing and unmet need for limiting) $=0$ and 'met need' (no unmet need, using for spacing and using for limiting) $=1$ [25].
The other explanatory variables were age, wealth status, education, marital status, and parity. Age was recorded as 15-19, 20-24, 25-29, 30-34, 35-39, 40-44, and 45-49. Wealth status was categorized into poorest, poorer, middle, richer, and richest. Education was classified into four categories: no education, primary education, secondary education, and higher education.

\section{Community level}

Three variables were considered at the contextual level, namely place of residence, socio-economic disadvantage, and sex of head of household. The socio-economic disadvantage variable was generated from the education and occupation variables and captured as tertile 1 (least disadvantaged), tertile 2 (moderate disadvantaged), and tertile 3 (most disadvantaged). The sex of the household head was captured as male and female.

\section{Statistical analysis}

We employed both descriptive and inferential analytical approaches. First, we computed the proportion of women who had ever terminated a pregnancy (see Table 1). Following the hierarchical nature of the data set, the Multilevel Logistic Regression Model (MLRM) was employed. This comprises fixed effects, and random effects [26]. The fixed effects/measures of associations of the model were gauged with binary logistic regression which resulted in odds ratios (ORs) and adjusted odds ratios (aORs) (see Table 2). The random-effects/ measures of variations, on the other hand, were assessed with Intra-Cluster Correlation (ICC) [27] (see Table 2). All the analyses were carried out using STATA version 13.0.

\section{Model fit and specifications}

We assessed the fitness of all the models with the Likelihood Ratio (LR) test. The presence of multicollinearity between the independent variables was checked before fitting the models. The variance inflation factor (VIF) test revealed the absence of high multicollinearity between the variables (Mean VIF $=2.98$ ).

\section{Results}

\section{Descriptive results}

Figure 1 shows the proportion of women with unmet/ met need for contraception that has ever terminated a pregnancy per country. On average, $28 \%$ of women in SSA have an unmet need for contraception. With regards to pregnancy termination, an average of $16 \%$ of women in SSA with unmet/met need for contraception had ever terminated a pregnancy, with Sierra Leone, recording the lowest proportion of $9 \%$ while Gabon had the highest proportion of $35 \%$. 
Table 1 Background characteristics and proportion ever terminated pregnancy

\begin{tabular}{|c|c|c|}
\hline Variables & Yes n (\%) & Total $\mathrm{n}$ \\
\hline \multicolumn{3}{|l|}{ Individual level } \\
\hline \multicolumn{3}{|c|}{ Unmet/met need for contraception } \\
\hline Unmet need & 15 & 74,584 \\
\hline Met need & 16 & 190,921 \\
\hline \multicolumn{3}{|l|}{ Age } \\
\hline $15-19$ & 6 & 29,207 \\
\hline $20-24$ & 10 & 55,129 \\
\hline $25-29$ & 15 & 59,644 \\
\hline $30-34$ & 18 & 49,175 \\
\hline $35-39$ & 21 & 38,685 \\
\hline $40-44$ & 24 & 22,974 \\
\hline $45-49$ & 25 & 10,691 \\
\hline \multicolumn{3}{|l|}{ Level of education } \\
\hline No education & 14 & 91,758 \\
\hline Primary & 17 & 86,903 \\
\hline Secondary & 16 & 74,997 \\
\hline Higher & 17 & 11,847 \\
\hline \multicolumn{3}{|l|}{ Marital status } \\
\hline Single & 8 & 31,155 \\
\hline Married & 15 & 176,358 \\
\hline Cohabitation & 21 & 43,548 \\
\hline Widowed & 18 & 2,750 \\
\hline Separated & 20 & 11,694 \\
\hline \multicolumn{3}{|l|}{ Parity } \\
\hline Zero birth & 11 & 30,494 \\
\hline One birth & 12 & 44,141 \\
\hline Two births & 15 & 43,479 \\
\hline Three births & 16 & 38,021 \\
\hline Four or more births & 19 & 109,370 \\
\hline \multicolumn{3}{|l|}{ Wealth status } \\
\hline Poorest & 15 & 56,782 \\
\hline Poorer & 16 & 53,050 \\
\hline Middle & 15 & 51,546 \\
\hline Richer & 16 & 51,410 \\
\hline Richest & 17 & 52,717 \\
\hline \multicolumn{3}{|l|}{ Community level } \\
\hline \multicolumn{3}{|l|}{ Place of residence } \\
\hline Urban & 17 & 94,643 \\
\hline Rural & 15 & 170,862 \\
\hline \multicolumn{3}{|l|}{ Sex of household head } \\
\hline Male & 16 & 204,517 \\
\hline Female & 15 & 60,988 \\
\hline \multicolumn{3}{|l|}{ Socio-economic disadvantage } \\
\hline Tertile 1 (Least disadvantage) & 16 & 88,828 \\
\hline Tertile 2 & 16 & 88,301 \\
\hline Tertile 3 (Most disadvantage) & 16 & 88,376 \\
\hline
\end{tabular}

Table 1 shows a summary of the explanatory variables and the proportion of women who had ever terminated a pregnancy. Pregnancy termination was higher among women with a met need for contraception (16\%), aged 45-49 (25\%), those with primary education (17\%), cohabiting women $(21 \%)$, and those with four or more births (19\%). Similarly, a greater section of women within the richest wealth quintile (17\%), had terminated pregnancies. At the community level, women who reside in urban areas $(17 \%)$, those with a male household head (16\%) and those in moderately disadvantaged socio-economic status $(16 \%)$ had a higher proportion of women who reported ever terminating a pregnancy.

\section{Fixed effects (measures of associations) results}

In Table 2, Model 3 is the complete model showing the association between the individual level, contextual level, and pregnancy termination among women in SSA. At the individual level, unmet need for contraception, age, education, marital status, parity, and wealth index showed significant associations with pregnancy termination. At the community level, place of residence, sex of household head, and socio-economic disadvantage showed significant association with pregnancy termination.

The likelihood of terminating a pregnancy was higher for women with a met need for contraception [aOR $=1.11 ; 95 \%$ CI $1.07-1.12$ ], as compared to their counterparts with unmet needs for contraception. Age was a strong factor in pregnancy termination with every additional age increasing the likelihood of pregnancy termination. Using no education as a reference, the likelihood of terminating a pregnancy increased with secondary education $[\mathrm{aOR}=1.33$; 95\% CI 1.28 1.37]. Cohabiting women were more likely to terminate a pregnancy $[\mathrm{aOR}=2.53$; 95\% CI $2.39-2.67$ ], as compared to those who were single. Women with four or more children were found to be less likely to terminate a pregnancy $[\mathrm{aOR}=0.62$; 95\% CI $0.59-0.66$ ] as compared to those with zero parity. Women in the richest wealth quintile $[\mathrm{aOR}=0.94 ; 95 \%$ CI $0.90-0.98$ ] were less likely to terminate a pregnancy relative to poorest women.

At the community level, the likelihood of terminating a pregnancy was low for women having female household heads $[\mathrm{aOR}=0.93 ; 95 \% \mathrm{CI} 0.91-0.96]$ and women who reside in rural areas $[\mathrm{aOR}=0.92 ; 95 \% \mathrm{CI} 0.91-0.96]$. On the contrary, moderately disadvantaged $[\mathrm{aOR}=1.09 ; 95 \%$ CI 1.05-1.14], and most disadvantaged [aOR $=1.10 ; 95 \%$ CI 1.06-1.15] women were likely to terminate a pregnancy compared to least socio-economically disadvantaged women. 
Table 2 Multilevel binary logistic regression results on the predictors of pregnancy termination among women with unmet/met need for contraception in sub-Saharan Africa

\begin{tabular}{|c|c|c|c|c|}
\hline Variables & Model 0 & Model 1 OR $(95 \% \mathrm{Cl})$ & Model 2 OR $(95 \% \mathrm{Cl})$ & Model 3 AOR $(95 \% \mathrm{Cl}$ \\
\hline \multicolumn{5}{|l|}{ Individual level } \\
\hline \multicolumn{5}{|l|}{ Unmet need for contraception } \\
\hline Unmet need & & 1 & & 1 \\
\hline Met need & & $1.11^{* * *}(1.07,1.12)$ & & $1.11^{* * *}(1.07,1.12)$ \\
\hline \multicolumn{5}{|l|}{ Age } \\
\hline $15-19$ & & 1 & & 1 \\
\hline $20-24$ & & $1.87^{* * *}(1.76,1.98)$ & & $1.87^{* * *}(1.77,1.98)$ \\
\hline $25-29$ & & $2.86^{* * *}(2.69,3.03)$ & & $2.87^{* * *}(2.71,3.04)$ \\
\hline $30-34$ & & $3.77^{* * *}(3.54,4.01)$ & & $3.79^{* * *}(3.55,4.03)$ \\
\hline $35-39$ & & $4.73^{* * *}(4.43,5.05)$ & & $4.76^{* * *}(4.46,5.08)$ \\
\hline $40-44$ & & $5.74 * * *(5.36,6.14)$ & & $5.78^{* * *}(5.39,6.18)$ \\
\hline $45-49$ & & $6.17^{* * *}(5.72,6.65)$ & & $6.22^{* * *}(5.77,6.71)$ \\
\hline \multicolumn{5}{|l|}{ Level of education } \\
\hline No education & & 1 & & 1 \\
\hline Primary & & $1.25^{* * *}(1.21,1.28)$ & & $1.25^{* * *}(1.22,1.29)$ \\
\hline Secondary & & $1.32^{* * *}(1.28,1.36)$ & & $1.33^{* * *}(1.28,1.37)$ \\
\hline Higher & & $1.13(1.07,1.20)$ & & $1.14(1.08,1.21)$ \\
\hline \multicolumn{5}{|l|}{ Marital status } \\
\hline Single & & 1 & & 1 \\
\hline Married & & $1.68^{* * *}(1.60,1.77)$ & & $1.66^{* * *}(1.58,1.75)$ \\
\hline Cohabitation & & $2.58^{* * *}(2.45,2.72)$ & & $2.53^{* * *}(2.39,2.67)$ \\
\hline Widowed & & $1.45^{* * *}(1.31,1.62)$ & & $1.49^{* * *}(1.34,1.67)$ \\
\hline Separated & & $2.14^{* * *}(2.00,2.31)$ & & $2.17^{* * *}(2.03,2.32)$ \\
\hline \multicolumn{5}{|l|}{ Parity } \\
\hline Zero birth & & 1 & & 1 \\
\hline One birth & & $0.75^{* * *}(0.71,0.79)$ & & $0.75^{* * *}(0.71,0.79)$ \\
\hline Two births & & $0.69^{* * *}(0.65,0.72)$ & & $0.69^{* * *}(0.65,0.72)$ \\
\hline Three births & & $0.63^{* * *}(0.61,0.67)$ & & $0.63^{* * *}(0.61,0.67)$ \\
\hline Four or more births & & $0.62^{* * *}(0.59,0.66)$ & & $0.62^{* * *}(0.59,0.66)$ \\
\hline \multicolumn{5}{|l|}{ Wealth status } \\
\hline Poorest & & 1 & & 1 \\
\hline Poorer & & $1.02(0.99,1.06)$ & & $1.02(0.99,1.05)$ \\
\hline Middle & & $0.97^{* * *}(0.94,1.01)$ & & $0.97^{* * *}(0.93,0.99)$ \\
\hline Richer & & $0.98^{* * *}(0.95,1.01)$ & & $0.95^{* * *}(0.92,0.99)$ \\
\hline Richest & & $0.99 * * *(0.96,1.03)$ & & $0.94^{* * *}(0.90,0.98)$ \\
\hline \multicolumn{5}{|l|}{ Community level } \\
\hline \multicolumn{5}{|l|}{ Place of residence } \\
\hline Urban & & & 1 & 1 \\
\hline Rural & & & $0.89^{* * *}(0.86,0.91)$ & $0.92^{* * *}(0.91,0.95)$ \\
\hline \multicolumn{5}{|l|}{ Sex of household head } \\
\hline Male & & & 1 & 1 \\
\hline Female & & & $0.93^{* * *}(0.91,0.95)$ & $0.93^{* * *}(0.91,0.96)$ \\
\hline \multicolumn{5}{|l|}{ Socio-economic disadvantage } \\
\hline Tertile 1 (Least disadvantage) & & & 1 & 1 \\
\hline Tertile 2 & & & $1.05^{*}(1.01,1.09)$ & $1.10^{* * *}(1.06,1.15)$ \\
\hline Tertile 3 (Most disadvantage) & & & $1.03(0.99,1.07)$ & $1.09^{* * *}(1.05,1.14)$ \\
\hline \multicolumn{5}{|l|}{ Random effect result } \\
\hline PSU variance $(95 \% \mathrm{Cl})$ & $0.02(0.1,0.02)$ & $0.02(0.02,0.03)$ & $0.02(0.01,0.02)$ & $0.02(0.02,0.03)$ \\
\hline
\end{tabular}


Table 2 (continued)

\begin{tabular}{lllll}
\hline Variables & Model $\mathbf{0}$ & Model 1 OR (95\% Cl) & Model 2 OR (95\% Cl) & Model 3 AOR (95\% Cl) \\
\hline ICC & 0.57 & 0.71 & 0.58 & 0.71 \\
LRTest & $x^{2}=158.11$ & $x^{2}=196.68$ & $X^{2}=157.85$ & $X^{2}=200.96$ \\
Wald chi-square & $p=0.0000$ & $p=0.0000$ & $p=0.0000$ & 75000 \\
Model fitness & & 7504.43 & 135.42 & 758.83 \\
Log-likelihood & & & $-114,671.1$ & $-110,472.8$ \\
BIC & $-114,738.7$ & $-110,515.6$ & 229417.1 & 221295.2 \\
AIC & 229502.3 & 221330.9 & 221295.5 \\
N & 229481.3 & 221079.1 & 229354.2 & 265,505 \\
\hline
\end{tabular}

$p<0.05{ }^{* *} p<0.01{ }^{* * *} p<0.001$

\section{Random effects (measures of variations) results}

The empty model (Model 0) revealed minimal variation in the probability of pregnancy termination with respect to the clustering of PSUs $\left(\sigma^{2}=0.02,95 \%\right.$ CI $\left.0.1,0.02\right)$. The empty model further indicated that $57 \%$ of the overall variance in pregnancy termination is attributable to inter-cluster variation of the characteristics $(\mathrm{ICC}=0.57)$. In the model 2 , the probability of pregnancy termination did not vary $\left(\sigma^{2}=0.02,95 \%\right.$ CI $\left.0.1,0.02\right)$. However, there was a rise in the overall variance in pregnancy termination attributable to inter-cluster variation of the characteristics $(71 \%)$. This indicates that the variation in pregnancy termination is highly attributable to differences or variations in factors at the community level as shown in Model 3.

\section{Discussion}

This study investigates the relationship between unmet/ met need for contraception and pregnancy termination in SSA. Unmet need for contraception, age, level of education, marital status, parity, wealth status, socioeconomic disadvantage, and sex of household, had a significant association with pregnancy termination.

On average, $16 \%$ of women in SSA had ever terminated a pregnancy, with Sierra Leone, recording the lowest proportion of $9 \%$ while Gabon had the highest proportion of $39 \%$. This is against the backdrop of Sierra Leone having a liberal abortion law that permits abortion under certain circumstances [28] while Gabon has a restrictive law on abortion [29]. This affirms the argument of Faundes and Shah [30] that women with unplanned pregnancy resort to abortion regardless of the laws, and countries with restrictive abortion laws record higher abortion rates. Hence, restrictive abortion laws may only force women to resort to unsafe abortion. We also found that women with a met need for contraception were more likely to terminate pregnancy compared to those who had an unmet need for contraception. This is consistent with a previous study by Amo-Adjei and Darteh [15] who reported that women with no unmet need for contraceptives had the highest odds of self-reported abortion in Ghana. A probable explanation of this is that contraceptives have a low failure risk [31] and this can translate into a high cumulative risk of unplanned pregnancies in a lifetime. There is therefore the chance of women being reluctant to utilise contraceptives due to previous failures [1]. Women with a met need for contraception may not necessarily be adhering to the prescription of contraceptives, hence increasing the risk of unplanned pregnancies. It is also worth mentioning that women with a met need for contraception might be relying on traditional methods which have a higher failure rate as compared to the modern methods [32]. This notwithstanding, the high rate of abortion among women with a met need for contraception could be attributed to women adopting postabortion contraception [33].

We found that as the age of women increased, the odds of pregnancy termination proliferated as reported by earlier studies [34-36]. This may be due to longer exposure to unprotected sexual intercourse and the failure of traditional contraceptives such as the rhythm and calendar methods. Evidence has shown that most older women do not use modern contraceptives and a failure of the traditional methods may lead to the termination of pregnancy [37]. A probable explanation is that older women have a complete family and consequently are more prone to medical termination of unplanned pregnancies.

Women with secondary education had higher odds of pregnancy termination compared with those with no formal education. This is consistent with earlier studies by Yaya et al. [38] and Chae et al. [39]. Women with secondary education are more probable to be exposed to the knowledge of abortion services and may know locations or places where termination of pregnancy could be carried out. They may also be enlightened about the dangers of complications and the need to have a safe abortion. 





Our study found a significant association between parity and pregnancy termination. Women with one birth and more were seen to have a lesser likelihood of pregnancy termination. Similar results were found in previous studies from Ghana and Mozambique [36, 40]. A possible explanation for this is that women in SSA are increasingly appreciating the importance of small family size [41]. We also found that women who had a female head of household reported a lower likelihood of pregnancy termination. This is inconsistent with the study of Izugbara [42]. This could be attributed to the fact that evidence on parent-child connectedness and or communication increasingly shows that women find it easier to discuss their sexual and reproductive health right (SRHR) issues with mothers or female guardians more than fathers or male guardians $[43,44]$.

Most socio-economically disadvantaged women had a higher likelihood of pregnancy termination. The possible explanation may be that possibly the most socio-economic disadvantaged may not have the means or wealth to take care of a baby. They may not be able to provide the nutritional and housing needs of the baby and hence the decision to terminate the pregnancy. It is possible that most socio-economically disadvantaged women may not want their children to experience the socio-economic hardship they are going through and hence the decision to terminate their pregnancies. Further, most socio-economically disadvantaged women may not have the financial capacity to afford a modern contraceptive and may be relying on traditional methods that have a higher failure rate [45].

\section{Strengths and limitations}

This study employs a rigorous analytical approach in investigating the underlying factors predicting pregnancy termination in SSA. We used large, representative datasets of countries in SSA and these strengthen the validity and generalisability of our findings. These notwithstanding, the study had some shortcomings. First, the cross-sectional design of the study did not allow causal inference between the predictors and pregnancy termination. Second, depending on the social and neighbourhood factors of the women, there is a possibility of social desirability bias in their responses.

\section{Conclusion}

The study has revealed that pregnancy termination persists among women in their reproductive age in SSA. Besides, women with a met need for contraception have higher odds of terminating a pregnancy. The underlying cause of this we argued could be poor adherence to the protocols of contraceptives or the reluctance of women to utilise contraceptives after experiencing a failure. This notwithstanding, pragmatic steps need to be taken to address the socio-economic disparities to promote the reproductive health and well-being of women. There is a need for efforts to intensify education on contraceptives and encourage adherence among women in their reproductive ages. Broader contextual factors need to be prioritised in the development of interventions aimed at mitigating pregnancy termination in SSA.

\section{Abbreviations \\ AIC: Akaike Information Criterion; BIC: Bayesian Information Criterion; DHS: Demographic and Health Survey; ICC: Intra-Cluster Correlation; LMICs: Lower- and middle-income countries; LR: Likelihood Ratio; MLRM: Multilevel Logistic Regression Model; PSU: Primary Sampling Unit; SRHR: Sexual and Reproductive Health Right; SSA: Sub-Saharan Africa.}

\section{Acknowledgements}

We appreciate the Measure DHS for granting us data for this study

\section{Authors' contributions}

KSA conceived the study and performed the analysis. EKA drafted the background. KSD drafted the discussion. JA reviewed multiple drafts and proposed additions and changes. KSA had the final responsibility to submit. All authors read and approved the final manuscript.

Funding

No funding was received for this study.

Availability of data and materials

Data used for the study is freely available to the public via https://dhsprogram. com/data/available-datasets.cfm.

\section{Declarations}

Ethics approval and consent to participate

Not applicable.

Consent for publication

Not applicable.

Competing interests

The authors declare that they have no competing interest.

Author details

${ }^{1}$ Department of Population and Health, College of Humanities and Legal Studies, University of Cape Coast, Cape Coast, Ghana. ${ }^{2}$ The Australian Centre for Public and Population Health Research, Faculty of Health, University of Technology Sydney, Sydney, NSW, Australia.

Received: 9 December 2020 Accepted: 18 August 2021

Published online: 28 August 2021

References

1. Sedgh G, Bearak J, Singh S, Bankole A, Popinchalk A, Ganatra B, Rossier C, Gerdts C, Tunçalp Ö, Johnson BR Jr, Johnston HB. Abortion incidence between 1990 and 2014: global, regional, and subregional levels and trends. Lancet. 2016;388(10041):258-67.

2. Munakampe MN, Zulu JM, Michelo C. Contraception and abortion knowledge, attitudes and practices among adolescents from low and middle-income countries: a systematic review. BMC Health Serv Res. 2018;18(1):909.

3. WHO. Preventing unsafe abortion; 2019. https://www.who.int/newsroom/fact-sheets/detail/preventing-unsafe-abortion. August 262020. 
4. Say L, Chou D, Gemmill A, Tunçalp Ö, Moller AB, Daniels J, Gülmezoglu AM, Temmerman M, Alkema L. Global causes of maternal death: a WHO systematic analysis. Lancet Glob Health. 2014;2(6):e323-33.

5. Vlassoff et al. Economic impact of unsafe abortion-related morbidity and mortality: evidence and estimation challenges. Brighton, Institute of Development Studies, 2008 (IDS Research Reports 59).

6. Faúndes A, Shah $\mathrm{H}$. Evidence supporting broader access to safe legal abortion. Int J Gynecol Obstet. 2015;131:S56-9.

7. United Nations. International Conference on Population and Development Programme of Action. UNFPA; 2014. https://www.unfpa.org/publicatio ns/international-conference-population-and-development-programmeaction. August 262020.

8. WHO. Unsafe abortion: global and regional estimates of the incidence of unsafe abortion and associated mortality in 2008. Geneva: WHO; 2011.

9. Gebremedhin M, Semahegn A, Usmael T, Tesfaye G. Unsafe abortion and associated factors among reproductive aged women in Sub-Saharan Africa: a protocol for a systematic review and meta-analysis. Syst Rev. 2018;7(1):130.

10. Haddad L. Unsafe abortion: unnecessary maternal mortality. Rev Obstet Gynecol. 2009;2(2):122-6.

11. Lauro D. Abortion and contraceptive use in sub-Saharan Africa: how women plan their families. Afr J Reprod Health. 2011;15(1):13.

12. United Nations, Department of Economic and Social Affairs, Population Division. World Family Planning 2017—highlights. (ST/ESA/SER.A/414); 2017.

13. Ahmed S, Choi Y, Rimon JG, Alzouma S, Gichangi P, Guiella G, Kayembe P, Kibira SP, Makumbi F, OlaOlorun F, Omoluabi E. Trends in contraceptive prevalence rates in sub-Saharan Africa since the 2012 London Summit on Family Planning: results from repeated cross-sectional surveys. Lancet Glob Health. 2019;7(7):e904-11.

14. United Nations, Department of Economic and Social Affairs, Population Division. Contraceptive Use by Method 2019: Data Booklet (ST/ESA/SER.A/435); 2019.

15. Amo-Adjei J, Darteh EK. Unmet/met need for contraception and selfreported abortion in Ghana. Sexual Reprod Healthcare. 2017:13:118-24.

16. Prata N, Holston M, Fraser A, Melkamu Y. Contraceptive use among women seeking repeat abortion in Addis Ababa, Ethiopia. Afr J Reprod Health. 2013;17(4):56.

17. Singh S, Bankole A, Darroch JE. The impact of contraceptive use and abortion on fertility in sub-Saharan Africa: estimates for 2003-2014. Popul Dev Rev. 2017;43(Suppl 1):141.

18. Levandowski BA, Mhango C, Kuchingale E, Lunguzi J, Katengeza H, Gebreselassie $\mathrm{H}$, Singh S. The incidence of induced abortion in Malawi. Int Perspect Sexual Reprod Health. 2013:39:88-96.

19. Corsi DJ, Neuman M, Finlay JE, Subramanian SV. Demographic and health surveys: a profile. Int J Epidemiol. 2012;41 (6):1602-13.

20. Ilboudo PG, Somda SM, Sundby J. Key determinants of induced abortion in women seeking postabortion care in hospital facilities in Ouagadougou, Burkina Faso. Int J Women's Health. 2014;6:565.

21. Lamina MA. Prevalence of abortion and contraceptive practice among women seeking repeat induced abortion in Western Nigeria. J Pregnancy. 2015;205:1.

22. Ganle JK, Obeng B, Yeboah JY, Tagoe-Darko E, Mensah CM. Disparities in abortion experience and access to safe abortion services in Ghana: evidence from a retrospective survey. Afr J Reprod Health. 2016;20(2):43-52.

23. Alemayehu B, Addissie A, Ayele W, Tiroro S, Woldeyohannes D. Magnitude and associated factors of repeat induced abortion among reproductive age group women who seeks abortion Care Services at Marie Stopes International Ethiopia Clinics in Addis Ababa, Ethiopia. Reprod Health. 2019;16(1):76

24. Seidu AA, Ahinkorah BO, Ameyaw EK, Hubert A, Agbemavi W, Armah-Ansah EK, Budu E, Sambah F, Tackie V. What has women's reproductive health decision-making capacity and other factors got to do with pregnancy termination in sub-Saharan Africa? Evidence from 27 cross-sectional surveys. Plos One. 2020;15(7):e0235329.

25. Ahinkorah BO. Predictors of unmet need for contraception among adolescent girls and young women in selected high fertility countries in sub-Saharan Africa: a multilevel mixed effects analysis. PloS One. 2020;15(8):e0236352.

26. Austin PC, Merlo J. Intermediate and advanced topics in multilevel logistic regression analysis. Stat Med. 2017;36(20):3257-77.
27. Merlo J, Wagner P, Ghith N, Leckie G. An original stepwise multilevel logistic regression analysis of discriminatory accuracy: the case of neighbourhoods and health. PloS one. 2016;11(4):e0153778.

28. Warriner IK, Shah $\mathbb{H}$, editors. Preventing unsafe abortion and its consequences: priorities for research and action. New York: Guttmacher Institute; 2006.

29. Lavelanet AF, Schlitt S, Johnson BR, Ganatra B. Global Abortion Policies Database: a descriptive analysis of the legal categories of lawful abortion. BMC Int Health Hum Rights. 2018;18(1):1. https://doi.org/10.1186/ s12914-018-0183-1.

30. Faundes A. Strategies for the prevention of unsafe abortion. Int J Gynaecol Obstet. 2012;119:568-71.

31. Trussell J. Contraceptive failure in the United States. Contraception. 2004;70(2):89-96

32. Sedgh G, Ashford LS, Hussain R. Unmet need for contraception in developing countries: examining women's reasons for not using a method. New York: Guttmacher Institute. 2016; 2:2015-6

33. Maxwell L, Voetagbe G, Paul M, Mark A. Does the type of abortion provider influence contraceptive uptake after abortion? An analysis of longitudinal data from 64 health facilities in Ghana. BMC Public Health. 2015;15(1):586.

34. Elul B. Determinants of induced abortion: an analysis of individual, household and contextual factors in Rajasthan, India. J Biosoc Sci. 2011;43(1):1-17.

35. Rambau NP. Levels and determinants of voluntary abortion in South Africa. Johannesburg: Doctoral dissertation, University of the Witwatersrand; 2016.

36. Dickson KS, Adde KS, Ahinkorah BO. Socio-economic determinants of abortion among women in Mozambique and Ghana: evidence from demographic and health survey. Arch Public Health. 2018;76(1):37. https://doi.org/ 10.1080/20786190.2014.977042.

37. Lasong J, Zhang Y, Gebremedhin SA, Opoku S, Abaidoo CS, Mkandawire $\mathrm{T}$, Zhao K, Zhang H. Determinants of modern contraceptive use among married women of reproductive age: a cross-sectional study in rural Zambia. BMJ Open. 2020;10(3):030980.

38. Yaya S, Amouzou A, Uthman OA, Ekholuenetale M, Bishwajit G, Udenigwe $\mathrm{O}$, Hudani A, Shah V. Prevalence and determinants of terminated and unintended pregnancies among married women: analysis of pooled crosssectional surveys in Nigeria. BMJ Glob Health. 2018;3(2): e000707. https:// doi.org/10.1136/bmjgh-2018-000707.

39. Chae S, Desai S, Crowell M, Sedgh G, Singh S. Characteristics of women obtaining induced abortions in selected low-and middle-income countries. PLoS ONE. 2017;12(3): e0172976. https://doi.org/10.1371/journal.pone. 0172976.

40. Seidu AA, Ahinkorah BO, Agbemavi W, Amu H, Bonsu F. Reproductive health decision-making capacity and pregnancy termination among Ghanaian women: analysis of the 2014 Ghana demographic and health survey. J Public Health. 2021;29(1):85-94.

41. Ameyaw EK, Budu E, Sambah F, Baatiema L, Appiah F, Seidu AA, Ahinkorah $B O$. Prevalence and determinants of unintended pregnancy in sub-Saharan Africa: a multi-country analysis of demographic and health surveys. PLoS ONE. 2019;14(8): e0220970. https://doi.org/10.1371/journal.pone.0220970.

42. Izugbara C. Socio-demographic risk factors for unintended pregnancy among unmarried adolescent Nigerian girls. South Afr Family Pract. 2015;57(2):121-5

43. Manu AA, Mba CJ, Asare GQ, Odoi-Agyarko K, Asante RK. Parent-child communication about sexual and reproductive health: evidence from the Brong Ahafo region, Ghana. Reprod Health. 2015;12(1):16. https://doi.org/10.1186/ S12978-015-0003-1.

44. Dessie Y, Berhane Y, Worku A. Parent-adolescent sexual and reproductive health communication is very limited and associated with adolescent poor behavioral beliefs and subjective norms: evidence from a community based cross-sectional study in eastern Ethiopia. PLoS ONE. 2015;10(7): e0129941. https://doi.org/10.1371/journal.pone.0129941.

45. Adam S, Hasstedt K, Kavanaugh ML, Anderson R. The social and economic benefits of women's ability to determine whether and when to have children; 2013.

\section{Publisher's Note}

Springer Nature remains neutral with regard to jurisdictional claims in published maps and institutional affiliations. 